\title{
The Effect of Heme Oxygenase on Ganglioside Redistribution Within Hepatocytes in Experimental Estrogen-Induced Cholestasis
}

\author{
T. PETR ${ }^{1}$, V. ŠMÍD ${ }^{1,2}$, V. KUČEROVÁ ${ }^{1}$, K. VÁŇOVÁ ${ }^{1}$, M. LENÍČEK ${ }^{1}$, L. VÍTEK $^{1,2}$, \\ F. ŠMÍD ${ }^{1}$, L. MUCHOVÁ ${ }^{1}$ \\ ${ }^{1}$ Institute of Medical Biochemistry and Laboratory Diagnostics, First Faculty of Medicine, Charles \\ University in Prague, Prague, Czech Republic, ${ }^{2}$ Fourth Department of Internal Medicine, First \\ Faculty of Medicine, Charles University in Prague, Prague, Czech Republic
}

Received September 23, 2013

Accepted December 13, 2013

On-line February 24, 2014

\begin{abstract}
Summary
Cholestasis is characterized by the elevation of serum total bile acids (TBA), which leads to the production of both free radicals and oxidative stress. Although they do not share the same mechanisms, membrane glycosphingolipids (GSL) and the antioxidant enzyme heme oxygenase-1 (HMOX1) both act against the pro-oxidative effect of TBA. The aim of the study was to assess the role of HMOX on GSL redistribution and composition within hepatocytes in the rat model of estrogen-induced cholestasis. Compared to the controls, an increase of total gangliosides in the liver homogenates of the cholestatic group $(P=0.001)$ was detected; further, it paralleled along with the activation of their biosynthetic b-branch pathway $(P<0.01)$. These effects were partially prevented by HMOX activation. Cholestasis was accompanied by a redistribution of GM1 ganglioside from the cytoplasm to the sinusoids; while HMOX activation led to the retention of GM1 in the cytoplasm $(P=0.014)$. Our study shows that estrogen-induced cholestasis is followed by changes in the synthesis and/or distribution of GSL. These changes are not only triggered by the detergent power of accumulated TBA, but also by their pro-oxidant action. Increases in the antioxidant defenses might represent an important supportive therapeutic measure for patients with cholestatic liver disease.
\end{abstract}

\section{Key words}

GM1 ganglioside - Heme oxygenase - Oxidative stress • Intrahepatic cholestasis $\bullet 17 a-$-ethinylestradiol

\section{Corresponding author}

Lucie Muchová, Institute of Medical Biochemistry and Laboratory
Diagnostics, $1^{\text {st }}$ Faculty of Medicine, Charles University in Prague, Na Bojisti 3, 12108 Prague 2, Czech Republic. Fax: [+420] 224 964 203. E-mail: lucie.muchova@If1.cuni.cz

\section{Introduction}

Estrogen-induced cholestasis is a pathological condition characterized by impaired bile flow and the accumulation of bile acids in the plasma of susceptible women, either after estrogen administration or in pregnancy (Vore 1987). Accumulated bile acids in the plasma and the livers of cholestatic individuals can cause liver injury through mechanisms including oxidative stress and structural and/or functional damage of the hepatocyte membrane, due to the detergent properties of bile acids (Kullak-Ublick and Meier 2000, Sokol et al. 2001, Roma et al. 2008, Fuentes-Broto et al. 2009).

Heme oxygenase (HMOX) is a rate-limiting enzyme in heme catabolism, which has antioxidative, anti-inflammatory, and cytoprotective properties. The beneficial effects of HMOX are mainly produced through its bioactive products - bilirubin and carbon monoxide (CO) (Vitek and Schwertner 2007, Muchova et al. 2011). $\mathrm{CO}$ is an important signaling molecule involved in bile secretion, as well as bile canaliculi contractility and liver perfusion; while bilirubin acts as a strong antioxidant, and can protect the liver directly against the oxidative stress triggered by bile acids (Reyes and Simon 1993, Muchova et al. 2011).

Gangliosides are glycosphingolipids (GSL), assembled from a lipophilic ceramide portion and 
structurally variable hydrophilic oligosaccharide portion containing $\mathrm{N}$-acetylneuraminic acid. Two main biosynthetic pathways of the gangliosides have been described in mammalian cells: 1] a-pathway comprising GM3, GM2, GM1, and GD1a gangliosides; and 2] bpathway with GD3, GD2, GD1b, and GT1b gangliosides (Kolter et al. 2002).

Gangliosides, as well as other GSL, are highly concentrated in the outer layer of the plasmatic membrane. Furthermore, gangliosides, thanks to their unique physical and chemical properties, are considered crucial molecules responsible for the rigidity of cell membranes (Pascher 1976, Harris et al. 1978, Pascher et al. 1992), as well as contributing to the protection against oxidative stress (Gavella et al. 2010).

More than 30 years ago, a decreased fluidity of the liver plasma membrane was observed in cholestasis that had been induced by ethinylestradiol (EE) (Balistreri et al. 1981, Smith and Gordon 1988); however, the possible consequences, resulting from the decreased fluidity of the cholestatic membrane, an increase in bpathway gangliosides, and the redistribution of GM1 ganglioside from the cytoplasm to the sinusoidal membrane of hepatocytes have only recently been described, in 2007 (Jirkovska et al. 2007, Majer et al. 2007). This supports the hypothesis that not only the increased synthesis of gangliosides, but also their redistribution in a situation of limited biosynthesis, may serve as a protective mechanism against the strong detergent effects of the bile acids accumulated during cholestasis.

The aim of the present study was to assess the potential role of HMOX on GSL redistribution and composition within hepatocytes in the rat model of ethinylestradiol-induced cholestasis.

\section{Materials and Methods}

\section{Chemicals}

Paraformaldehyde, cholera toxin B-subunit biotin-labeled (ChT-B-biotin), streptavidin-peroxidase polymer, albumin, biotin, $17 \alpha$-ethinylestradiol, hemin, Nacetylneuraminic acid, ammonium acetate, PAP pen for immunostaining, monosialoganglioside GM1 from bovine brain, 1,2-propanediol, diaminobenzidine (DAB)tetrahydrochloride tablets, and RNAlater were all supplied by Sigma Aldrich (St. Louis, MO, USA); avidin and N,N-dimethylformamide were obtained from Fluka (Buchs, Switzerland); the DEAE Sephadex was supplied by GE Healthcare (Little Chalfont, UK). High Performance Silica Plates, resorcinol, and silica gel 60 came from Merck (Darmstadt, Germany); the Faramount Mounting Medium was received from Dako (Glostrup, Denmark); the Total RNA Purification Kit was from Norgen Biotek Corporation (Thorold, Canada); the High Capacity cDNA Reverse Transcription Kit and TaqMan Gene Expression Master Mix were from Applied Biosystems (Foster City, USA). All other chemicals were purchased from Penta (Prague, Czech Republic).

\section{Experimental animals}

Female Wistar rats were obtained from Anlab (Prague, Czech Republic), and housed under a controlled temperature and with a natural light-dark cycle. The animals had free access to water and food throughout the experiment. They were forced to fast overnight before the experiment.

Cholestasis was induced by subcutaneous injections of EE $(5 \mathrm{mg} / \mathrm{kg})$ diluted in 1,2-propanediol, and applied daily for 18 days (E group). The control groups $(\mathrm{C})$ only received the 1,2-propanediol. Activation of HMOX1 (aE group) was achieved by intraperitoneal administration of heme $(15 \mu \mathrm{mol} / \mathrm{kg}$ in 4 doses on days 0 , 5,10 , and 15). The heme was dissolved in $0.1 \mathrm{M} \mathrm{NaOH}$, stabilized by albumin solution $(1.5 \mathrm{mmol} / 1$ heme: 0.15 $\mathrm{mmol} / 1 \mathrm{BSA}$ ), and then adjusted by $0.1 \mathrm{M} \mathrm{HCl}$ to a final $\mathrm{pH}$ of 7.4. The minimum number of animals per group was $n=6$.

After intramuscular anesthesia with ketamine (90 $\mathrm{mg} / \mathrm{kg})$ and xylazine $(10 \mathrm{mg} / \mathrm{kg})$, the animals were sacrificed, and blood was then obtained from the inferior vena cava for biochemical analyses. Their livers were weighed and then immediately processed for histochemical analysis, isolation of gangliosides and RNA, as well as the determination of HMOX activity.

All aspects of the study met all of the accepted criteria for the experimental use of laboratory animals; all protocols were approved by the Animal Research Committee of the First Faculty of Medicine, Charles University in Prague, Prague, Czech Republic.

Determination of serum markers of liver injury and HMOX activity

The following serum markers of cholestasis and hepatocellular injury were evaluated: total bile acids (TBA), total bilirubin (Bili-T); the activities of alkaline phosphatase (ALP), aspartate aminotransferase (AST), and alanine aminotransferase (ALT). TBA levels were 
determined spectrophotometrically using a Bile Acids kit (Trinity Biotech, Jamestown, NY, USA), all of the other markers were determined on an automatic analyzer (Modular analyzer, Roche Diagnostics $\mathrm{GmbH}$, Mannheim, Germany). HMOX activity was measured by gas chromatography, as previously described (Vreman and Stevenson 1988, 2001), and calculated as pmol $\mathrm{CO} / \mathrm{h} / \mathrm{mg}$ fresh weight.

\section{Peroxyl radical scavenging capacity}

The peroxyl radical scavenging capacity of the rat serum was detected fluorometrically as the proportion of chain-breaking antioxidant consumption present in the serum, relative to that of Trolox (a reference and calibration antioxidant compound), as previously described (Iuliano et al. 2000).

\section{Analysis of liver gangliosides}

The chloroform-methanol extraction of glycolipids from the liver tissue was performed according to Ledeen et al. (1973), with minor modifications by Ueno et al. (1978). The extract was purified on a silica gel column, again following the method of Leeden et al. (1973). An additional purification of the samples using a Folch partition (Folch et al. 1957) was necessary for the removal of heme in the aE samples. This substance has a similar mobility in thin layer chromatography (TLC) as gangliosides, and might interfere with the densitometric measurement. Part of the extract was used for the determination of the total sialic acid (total gangliosides) by the photometric method with resorcinol reagent (Svennerholm 1957, Takki-Luukkainen and Miettinen 1959), the other part was used for TLC quantification of the content of the major gangliosides. GM1 ganglioside, with a known concentration, was applied onto each HPTLC plate in order to correct for any differences caused by the intensity of spraying with the resorcinol $\mathrm{HCl}$ reagent. The densitometric measurement was evaluated using CATs3 software (CAMAG, Switzerland).

\section{Determination of glycosyltransferases expression}

Total liver RNA was isolated from samples stored in RNAlater tissue storage reagent (Sigma Aldrich, St. Louis, USA) using a Total RNA Purification kit (Norgen Biotek Corporation, Canada); and cDNA was generated using a High Capacity cDNA Reverse Transcription kit (Applied Biosystems, Foster City, USA). Real-time PCR was performed with a TaqMan ${ }^{\circledR}$
Gene Expression Assay Kit (Applied Biosystems, Foster City, USA) for sialyltransferase II (St8Sial, Rn00563093_m1) and galactosyltransferase II (B4Galt2, Rn01417399_m1). Data were normalized to $\beta$-actin (Actb, Rn00667869_m1) and expressed as fold change from the control levels.

\section{Histochemical detection of GM1 ganglioside in rat liver}

Microscopic distribution of GM1 ganglioside (the representative of GSL) was studied in the liver tissue sections by histochemical detections, based on the strong binding of the cholera toxin B-subunit to GM1. Blocks of liver tissue were collected from each animal, frozen, and cryostat sections (6 $\mu \mathrm{m}$ thick) were prepared from all blocks. Each animal was represented by six sections.

Before histochemical detection, the slides with sections were fixed with anhydrous acetone and $4 \%$ formaldehyde, as described by Petr et al. (2010). GM1 ganglioside was detected by a histochemical reaction with ChT-B-biotin (diluted 1:500 in PBS with 3\% BSA), followed by incubation with streptavidin-peroxidase polymer, diluted 1:400 in PBS. Peroxidase activity was visualized using diaminobenzidine tetrahydrochloride.

\section{Image analysis of the liver sections}

Selected areas from each slide were photographed with an objective magnification of $40 \mathrm{X}$ $(\mathrm{NA}=500)$. Photographs were taken under constant conditions. The entire area was systematically inspected, and every sixth to seventh screen was photographed using the stratified random sampling method (Hamilton 1995). Lumens of large vessels and artificially damaged areas were excluded from the analysis. The sinusoidal membrane of hepatocytes ( $\sin$ ) and adjacent areas of the cytoplasm (cyt) were traced and subsequently measured. The optical density of the GM1 reaction product was determined using a computer image analysis program ACC 6.0 (SOFO, Czech Republic).

\section{Statistical analysis}

Normally distributed data are presented as the mean $\pm \mathrm{SD}$, and were analyzed using Student's t-test; skewed data are expressed as the median and $95 \% \mathrm{CI}$, and were analyzed by the Mann-Whitney Rank Sum test. Kruskal Wallis ANOVA with post hoc analysis was used for multiple comparisons. Differences with $\mathrm{P}<0.05$ were considered statistically significant. The analyses were performed using STATISTICA CZ software, v. 10. 


\section{Results}

HMOX activation increases serum antioxidant capacity of cholestatic animals

As expected, EE exposure resulted in significant increases of serum Bili-T (1.0 \pm 0.3 vs. $3.2 \pm 2.0 \mu \mathrm{mol} / 1$, $\mathrm{P}=0.005), \quad$ TBA $\quad(5.5 \pm 5.3 \quad$ vs. $115.2 \pm 71.3 \mu \mathrm{mol} / 1$, $\mathrm{P}=0.005)$, and $\operatorname{ALP}(1.8 \pm 0.4$ vs. $3.2 \pm 0.9 \mu \mathrm{kat} / \mathrm{l}, \mathrm{P}=0.008)$, compared to the corresponding controls. Administration of heme, a specific inducer of HMOX1, substantially increased liver HMOX activity in the EE-treated group (261.2 \pm 129.1 vs. $434.9 \pm 143.7 \mathrm{pmol} \mathrm{CO} / \mathrm{h} / \mathrm{mg} \mathrm{FW}$, $\mathrm{P}=0.031)$.

To investigate whether HMOX induction can increase the total antioxidant status of experimental animals, we measured the serum antioxidant capacity of cholestatic rats exposed to heme. Indeed, the heme administration increased the peroxyl radical scavenging capacity of the sera of EE-treated animals by $68 \%$ ( $\mathrm{P}=0.016$, Fig. 1).

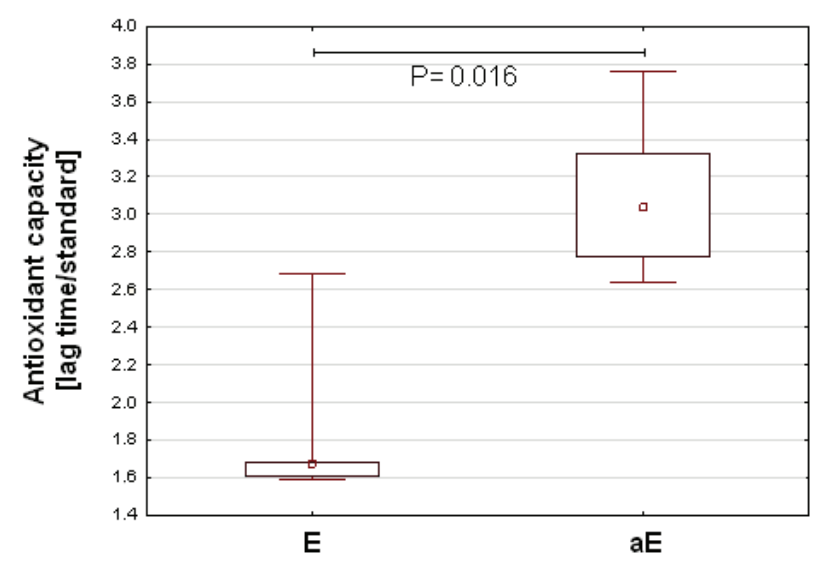

Fig. 1. The effect of HMOX induction on serum antioxidant capacity of estrogen-exposed animals. Data are expressed as a ratio between the lag time of the serum to that of the standard (Trolox), presented as median, 25-75\% (boxes) and 5-95\% (whiskers). $\mathrm{E}$, estrogen-exposed animals; $\mathrm{aE}$, estrogen-exposed animals treated with heme

HMOX activation prevents an increase of total ganglioside content in the cholestatic liver

Total liver gangliosides (measured as total sialic acid content) were significantly elevated in the cholestatic samples, compared to control group C [40.3 (27.4-49.9) vs. $17.0(8.9-26.5) \mathrm{nmol} / \mathrm{g}, \mathrm{P}=0.001]$. A much smaller and non-significant increase in the total liver ganglioside content has been observed in the cholestatic samples treated with heme [17.0 (8.9-26.5) vs. 31.9 (16.9-36.8) $\mathrm{nmol} / \mathrm{g}, \mathrm{P}>0.05]$ (Fig. 2).

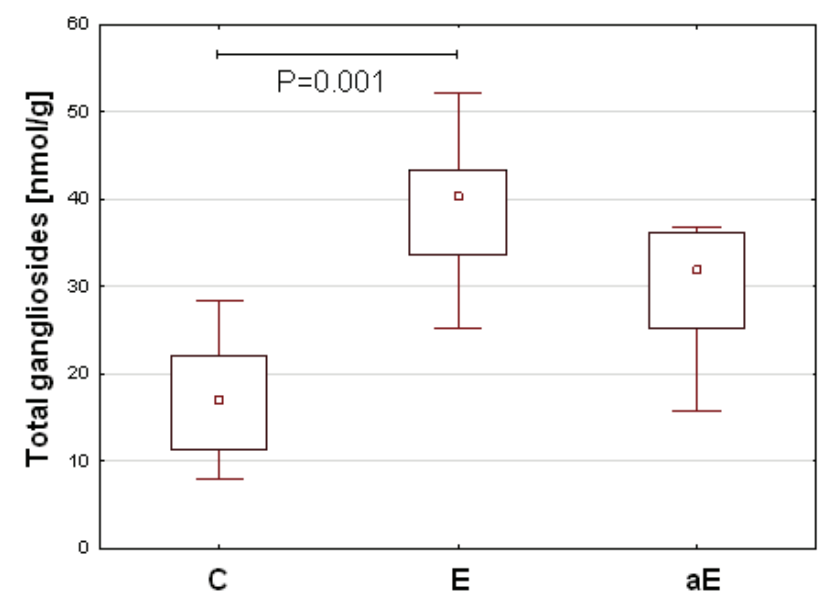

Fig. 2. The effect of HMOX induction on total liver gangliosides of cholestatic animals. Liver content of total gangliosides, expressed as median, 25-75\% (boxes) and 5-95\% (whiskers). C, control animals; $E$, estrogen-exposed animals; $a E$, estrogenexposed animals treated with heme

Activation of b-terminal branch of ganglioside synthesis in cholestasis is prevented by HMOX

In this set of experiments, we measured changes in the concentration of individual liver gangliosides after induction of cholestasis and HMOX activation.

No changes in the concentration of gangliosides of the a-biosynthetic pathway (GM1 and GD1a) were observed. However, a significant activation of the terminal part of the b-branch gangliosides (represented by a two-fold increase of GD1b and GT1b, P=0.005 and $\mathrm{P}<0.001$, respectively) was detected in the cholestatic animals. Interestingly, this activation was partially prevented by HMOX activation, only when mild increases in GD1b and GT1b were observed (Fig. 3).

To determine the rates of activation of the a- and b-branch of ganglioside biosynthetic pathways, we studied the relative expressions of galactosyltransferase II (unspecific GM1-synthase) and sialyltransferase II (specific GD3-synthase) in liver homogenates. Compared to controls, no significant changes were observed in the expression of GM1-synthase in the livers of cholestatic animals $(98 \pm 27 \%$ and $113 \pm 43 \%$ in $\mathrm{E}$ and $\mathrm{aE}$, respectively, $\mathrm{P}>0.05$ ). On the other hand, the expression of GD3-synthase, showing an activation of the bbiosynthetic branch, was markedly increased in the cholestatic samples $(230 \pm 77 \%$ of controls, $\mathrm{P}=0.04)$. This increase was not as pronounced when HMOX had been activated in the cholestatic animals (increased only to $186 \pm 84 \%, \mathrm{P}>0.05$ ) (Fig. 3). 


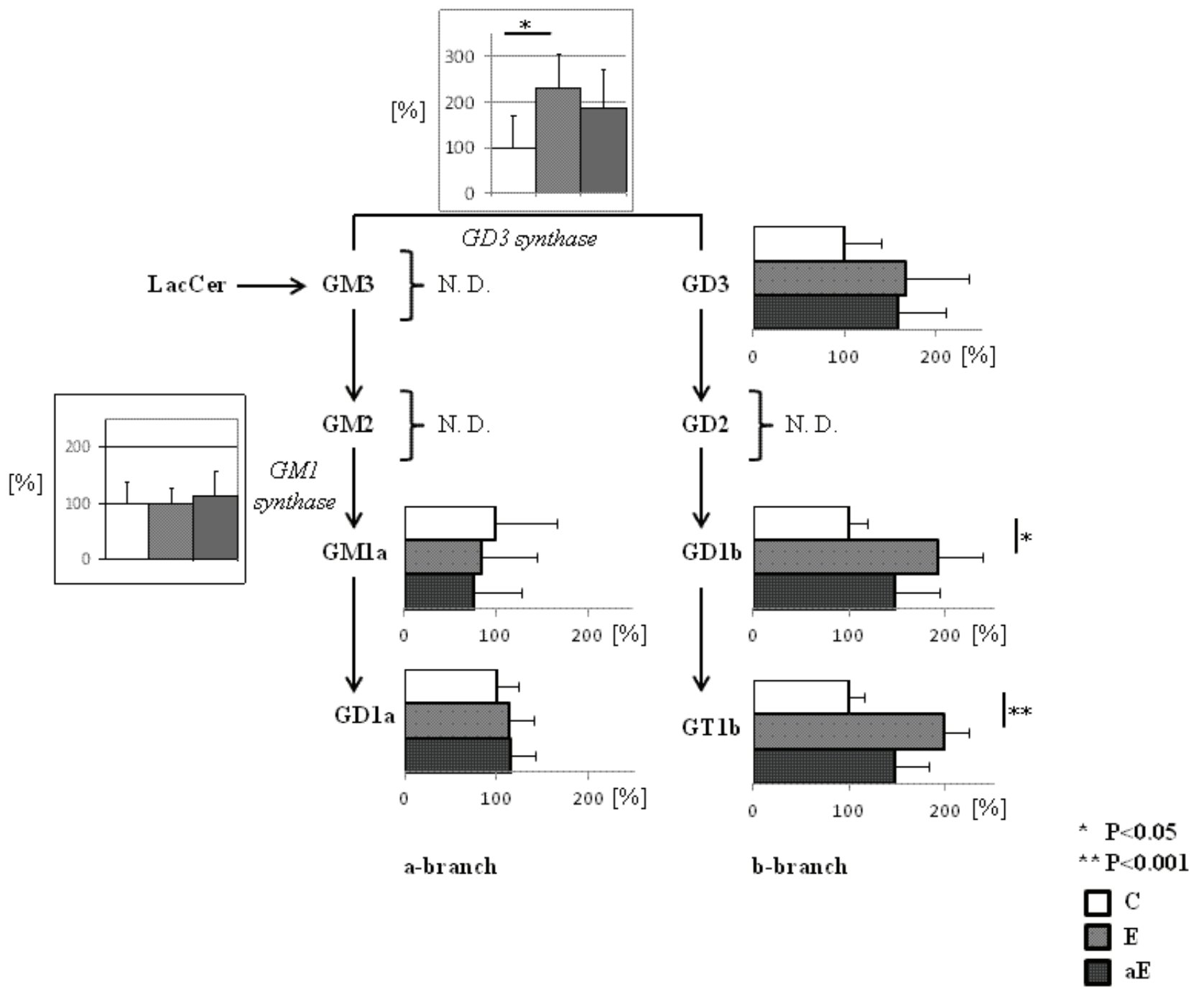

Fig. 3. Induction of ganglioside biosynthesis in cholestatic hepatocytes. Relative liver content of individual gangliosides of a- and bbiosynthetic pathways, and relative expressions of key enzymes in ganglioside synthesis. ND, not detected; LacCer, lactosylceramide (precursor of ganglioside synthesis); C, control animals; E, estrogen-exposed animals; aE, estrogen-exposed animals treated with heme

HMOX induction affects the GM1 distribution in the cholestatic hepatocyte

To study the changes in the distribution of glycolipids within the liver cell after cholestatic liver injury and HMOX activation, we measured the histochemical localization of GM1 ganglioside (the representative of GSL) in the liver sections.

When compared to the controls, cholestasis was accompanied by a substantial shift of GM1 ganglioside from the cytoplasm to the sinusoidal membrane. Pretreatment with heme completely abolished this effect; GM1 staining increased in the cytoplasm, but was substantially reduced in membranes (Fig. 4).

This observation was quantified by the image analysis of GM1 in the subsinusoidal compartment of the cytoplasm (cyt) and the sinusoidal membranes (sin) of hepatocytes. Based on this analysis, the sin/cyt ratio was calculated, indicating the relative distribution of glycolipids within the liver cell. The results clearly show the shift of GM1 ganglioside from the cytoplasm to membranes in cholestatic samples (sin/cyt ratio $1.51 \pm 0.19$ vs. $1.71 \pm 0.10, \mathrm{P}=0.65$ ); while the shift was reversed by HMOX induction (sin/cyt ratio $1.71 \pm 0.10$ vs. $1.31 \pm 0.04, \mathrm{P}=0.014$ ) (Fig. 5).

\section{Discussion}

The present study shows that in estrogeninduced cholestasis, it is not only the detergent properties, but also the pro-oxidant properties of the accumulated bile acids that are responsible for increased synthesis and membrane distribution of gangliosides. If the antioxidative response is augmented, the cholestatic pattern of the liver gangliosides is partially reversed. 


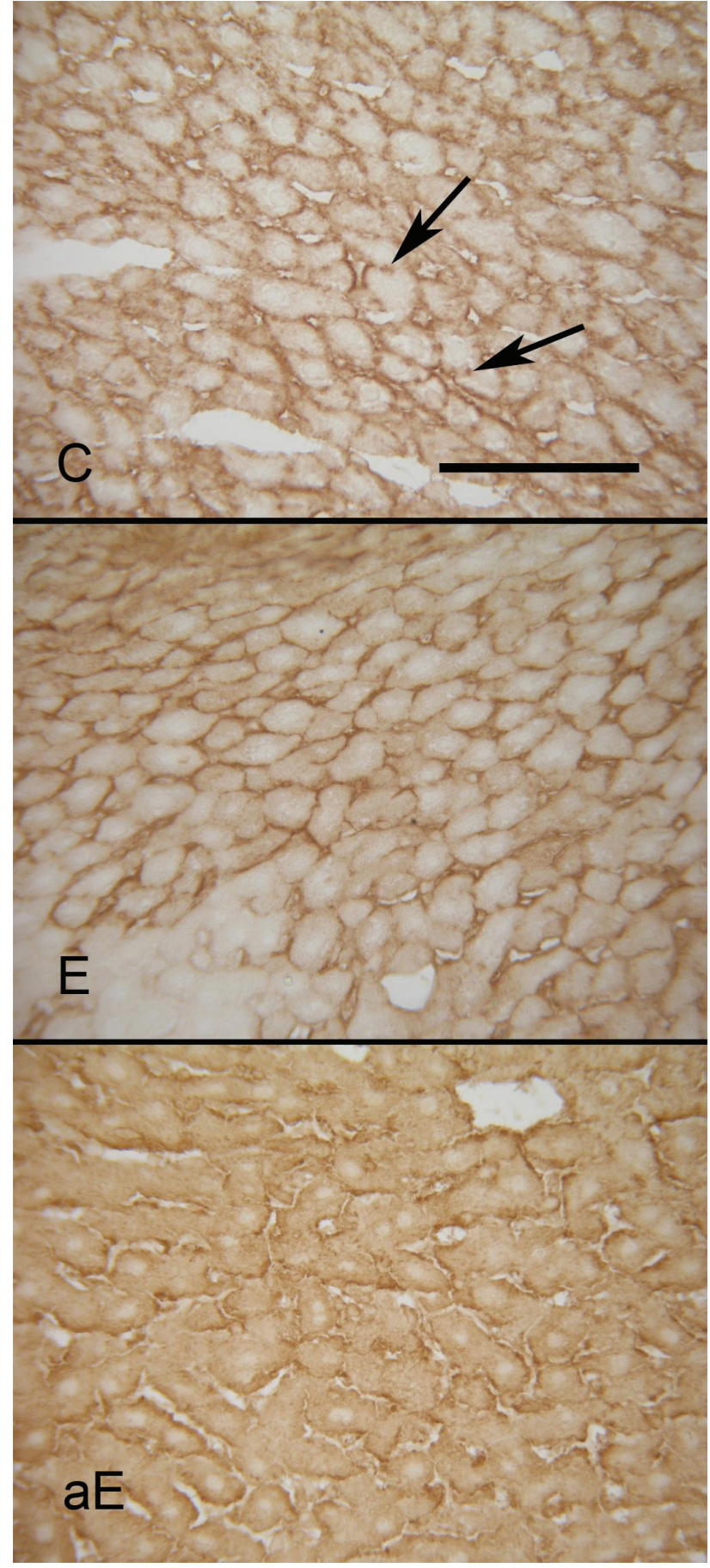

Fig. 4. The effect of HMOX1 induction on GM1 localization in the cholestatic liver. GM1 in the liver sections was detected using ChT-B-biotin with streptavidin-peroxidase polymer, and visualized using diaminobenzidine tetrahydrochloride (brown color). The apparent shift of GM1 positivity from sinusoidal and canalicular membrane (arrowheads) in control group (C) to sinusoidal membrane, only in the cholestatic group (E); or to the cytoplasm in the cholestatic group with activated HMOX1 (aE) can be observed. Bar $=100 \mu \mathrm{m}$. C, control animals; $\mathrm{E}$, estrogen-exposed animals; $\mathrm{aE}$, estrogen-exposed animals treated with heme

To investigate whether oxidative stress, increased by accumulated bile acids in estrogen-induced cholestasis is responsible for changes in liver ganglioside

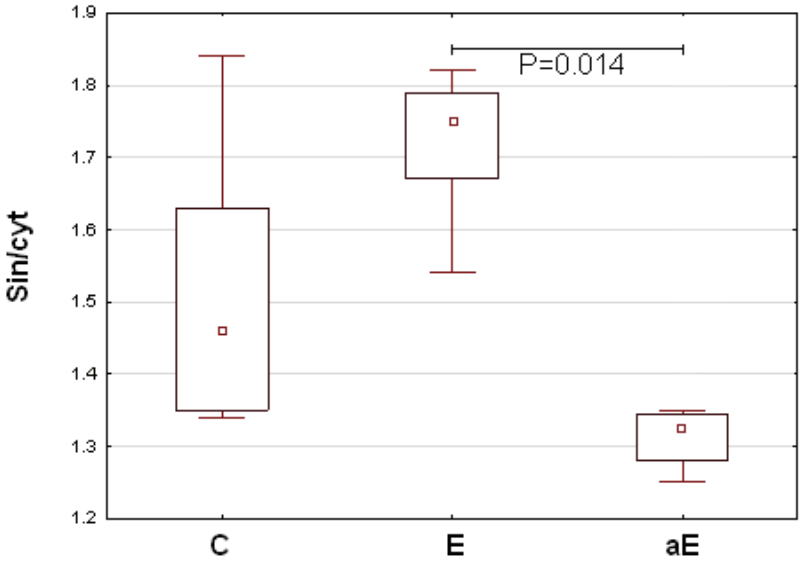

Fig. 5. The effect of HMOX1 induction on redistribution of GM1 ganglioside within the liver cells. Image analysis of the intensity of GM1 staining in the subsinusoidal compartment of cytoplasm (cyt) and sinusoidal membranes (sin) of hepatocytes, expressed as sin/cyt ratio. C, control animals; $E$, estrogen-exposed animals; $\mathrm{aE}$, estrogen-exposed animals treated with heme

metabolism, we used an experimental model with activation of the antioxidant enzyme HMOX. We found that administration of the HMOX substrate, heme, to EEtreated animals leads to a significant increase in the serum antioxidant capacity. As we have recently shown (Zelenka et al. 2012), activation of HMOX is associated, via formation of its bioactive products, with strong cytoprotective and antioxidant actions, counteracting the pro-oxidative effect of accumulated bile acids in cholestasis (Muchova et al. 2011).

In agreement with data published earlier by our group (Majer et al. 2007), we observed an increase in ganglioside synthesis (measured as sialic acid content) and the activation of b-branch ganglioside biosynthesis in cholestatic livers. Gangliosides, due to their physical chemical properties, protect cells against harmful extrinsic factors by forming detergent-resistant and rigid domains in the outer leaflet of the plasma membrane (Kanfer and Hakomori 1983, Hakomori 2003). Thus, the increase in total ganglioside content, and particularly the b-series of gangliosides (containing more sialic acid molecules) in cholestatic animals might be a logical response to this insult. Interestingly, antagonizing the pro-oxidative actions of bile acids by HMOX activation in cholestatic animals tended to reverse this increase towards values closer to those of the controls. Considering reports emphasizing the antioxidant properties of gangliosides (Avrova et al. 1998, Gavella et al. 2007), and the effect of GM1 ganglioside on membrane fluidity in primary rat hepatocytes (Sergent $e t$ al. 2005), we speculate that oxidative stress might be an 
important factor in regulating ganglioside biosynthesis and membrane stabilization during estrogen-induced cholestasis.

Cholestasis is not only characterized by an increase in ganglioside biosynthesis, but also by their shift from the cytoplasm to the plasma membrane (Jirkovska et al. 2007). In accord with this data, we observed the highest membrane GM1 ganglioside content in cholestatic livers. On the other hand, in estrogentreated animals with HMOX induction, gangliosides did not follow the cholestatic pattern, and a significant drop in membrane ganglioside content was observed.

There are some limitations of our study. First, we can only speculate on the role of GSL redistribution within the membrane of hepatocyte. GSL are part of dynamic membrane rafts having not only protective properties against detergent effects of bile acids but also important signaling functions. This topic needs to be addressed in future studies. Secondly, to clarify the exact role of HMOX on GSL metabolism, further studies with HMOX knock-out animals should be performed.

We conclude that estrogen-induced cholestasis is followed by changes in the synthesis and/or distribution of gangliosides within the hepatocyte. These changes are not only triggered by the detergent properties of highly concentrated bile acids, but also by oxidative stress, and thus might represent a general mechanism of hepatoprotection. Therefore, enhancement of the antioxidative defense mechanisms by HMOX induction might represent an important supportive therapeutic measure under cholestatic liver conditions.

\section{Conflict of Interest}

There is no conflict of interest.

\section{Acknowledgements}

We thank Jaroslava Šmídová for preparation of the cryostat sections and help with the immunohistochemical staining; Olga Švejdová and Magdalena Kadlecová for their excellent technical assistance. This research was supported by grants from the Charles University in Prague, Czech Republic, (GAUK 251207; SVV 2665162013 and PRVOUK-P25/LF1/2); and from the Internal Grant Agency of the Ministry of Health of the Czech Republic, (IGA MZ NT11327-4/2010).

\section{Abbreviations}

GSL, glycosphingolipids; HMOX, heme oxygenase; GM1, II $^{3} \mathrm{NeuAc-GgOse}{ }_{4} \mathrm{Cer} ; \quad$ GM2, II ${ }^{3} \mathrm{NeuAc-}$ $\mathrm{GgOse}_{3} \mathrm{Cer}$; GM3, II NeuAc-LacCer; GD1a, $\mathrm{IV}^{3} \mathrm{NeuAc}, \mathrm{II}^{3} \mathrm{NeuAc-GgOse}{ }_{4} \mathrm{Cer} ; \quad$ GD3, $\mathrm{II}^{3}(\mathrm{NeuAc})_{2}-$ LacCer; GD2, II ${ }^{3}(\mathrm{NeuAc})_{2}-\mathrm{GgOse}_{3} \mathrm{Cer} ; \quad \mathrm{GD} 1 \mathrm{~b}$, $\mathrm{II}^{3}(\mathrm{NeuAc})_{2}-\mathrm{GgOse}_{4} \mathrm{Cer} ; \mathrm{GT} 1 \mathrm{~b}, \mathrm{IV}^{3} \mathrm{NeuAc}, \mathrm{II}^{3}(\mathrm{NeuAc})_{2}-$ $\mathrm{GgOse}_{4} \mathrm{Cer}$; LacCer, lactosylceramide; EE, $17 \alpha-$ ethinylestradiol; ChT-B-biotin, cholera toxin B-subunit biotin-labeled; TBA, total bile acids; Bili-T, total bilirubin; ALP, alkaline phosphatase; AST, aspartate aminotransferase; ALT, alanine aminotransferase

\section{References}

AVROVA NF, VICTOROV IV, TYURIN VA, ZAKHAROVA IO, SOKOLOVA TV, ANDREEVA NA, STELMASCHUK EV, TYURINA YY, GONCHAR VS: Inhibition of glutamate-induced intensification of free radical reactions by gangliosides: possible role in their protective effect in rat cerebellar granule cells and brain synaptosomes. Neurochem Res 23: 945-952, 1998.

BALISTRERI WF, LESLIE MH, COOPER RA: Increased cholesterol and decreased fluidity of red cell membranes (spur cell anemia) in progressive intrahepatic cholestasis. Pediatrics 67: 461-466, 1981.

FOLCH J, LEES M, SLOANE STANLEY GH: A simple method for the isolation and purification of total lipides from animal tissues. J Biol Chem 226: 497-509, 1957.

FUENTES-BROTO L, MARTINEZ-BALLARIN E, MIANA-MENA J, BERZOSA C, PIEDRAFITA E, CEBRIAN I, REITER RJ, GARCIA JJ: Lipid and protein oxidation in hepatic homogenates and cell membranes exposed to bile acids. Free Radic Res 43: 1080-1089, 2009.

GAVELLA M, KVEDER M, LIPOVAC V, JURASIN D, FILIPOVI-VINCEKOVIC N: Antioxidant properties of ganglioside micelles. Free Radic Res 41: 1143-1150, 2007.

GAVELLA M, KVEDER M, LIPOVAC V: Modulation of ROS production in human leukocytes by ganglioside micelles. Braz J Med Biol Res 43: 942-949, 2010.

HAKOMORI S: Structure, organization, and function of glycosphingolipids in membrane. Curr Opin Hematol 10: 1624, 2003. 
HAMILTON PW: Designing a morphometric study. In: Quantitative Clinical Pathology. PW HAMILTON, DC ALLEN (eds), Blackwell Science, Oxford, 1995, pp 311-315.

HARRIS PL, HARVEY DR, BLISS BP: The importance of plasma lipid, glucose, insulin and fibrinogen in femoropopliteal surgery. Br J Surg 65: 197-200, 1978.

IULIANO L, PICCHERI C, COPPOLA I, PRATICO D, MICHELETTA F, VIOLI F: Fluorescence quenching of dipyridamole associated to peroxyl radical scavenging: a versatile probe to measure the chain breaking antioxidant activity of biomolecules. Biochim Biophys Acta 1474: 177-182, 2000.

JIRKOVSKA M, MAJER F, SMIDOVA J, STRITESKY J, SHAIK GM, DRABER P, VITEK L, MARECEK Z, SMID F: Changes in GM1 ganglioside content and localization in cholestatic rat liver. Glycoconj $J$ 24: 231$241,2007$.

KANFER JN, HAKOMORI S: Glycosphingolipids in cellular interaction, differentiation, and oncogenesis. In: Sphingolipid Biochemistry. JN KANFER, S HAKOMORI (eds), Planeum Press, New York, 1983, pp 327-379.

KOLTER T, PROIA RL, SANDHOFF K: Combinatorial ganglioside biosynthesis. J Biol Chem 277: 25859-25862, 2002.

KULLAK-UBLICK GA, MEIER PJ: Mechanisms of cholestasis. Clin Liver Dis 4: 357-385, 2000.

LEDEEN RW, YU RK, ENG LF: Gangliosides of human myelin: sialosylgalactosylceramide (G7) as a major component. J Neurochem 21: 829-839, 1973.

MAJER F, TRNKA L, VITEK L, JIRKOVSKA M, MARECEK Z, SMID F: Estrogen-induced cholestasis results in a dramatic increase of b-series gangliosides in the rat liver. Biomed Chromatogr 21: 446-450, 2007.

MUCHOVA L, VANOVA K, ZELENKA J, LENICEK M, PETR T, VEJRAZKA M, STICOVA E, VREMAN HJ, WONG RJ, VITEK L: Bile acids decrease intracellular bilirubin levels in the cholestatic liver: implications for bile acid-mediated oxidative stress. J Cell Mol Med 15: 1156-1165, 2011.

PASCHER I: Molecular arrangements in sphingolipids. Conformation and hydrogen bonding of ceramide and their implication on membrane stability and permeability. Biochim Biophys Acta 455: 433-451, 1976.

PASCHER I, LUNDMARK M, NYHOLM PG, SUNDELL S: Crystal structures of membrane lipids. Biochim Biophys Acta 1113: 339-373, 1992.

PETR T, SMID V, SMIDOVA J, HULKOVA H, JIRKOVSKA M, ELLEDER M, MUCHOVA L, VITEK L, SMID F: Histochemical detection of GM1 ganglioside using cholera toxin-B subunit. Evaluation of critical factors optimal for in situ detection with special emphasis to acetone pre-extraction. Eur J Histochem 54: 112-117, 2010.

REYES H, SIMON FR: Intrahepatic cholestasis of pregnancy: an estrogen-related disease. Semin Liver Dis 13: 289301, 1993.

ROMA MG, CROCENZI FA, SANCHEZ POZZI EA: Hepatocellular transport in acquired cholestasis: new insights into functional, regulatory and therapeutic aspects. Clin Sci (Lond) 114: 567-588, 2008.

SERGENT O, PEREIRA M, BELHOMME C, CHEVANNE M, HUC L, LAGADIC-GOSSMANN D: Role for membrane fluidity in ethanol-induced oxidative stress of primary rat hepatocytes. $J$ Pharmacol Exp Ther 313: 104-111, 2005.

SMITH DJ, GORDON ER: Role of liver plasma membrane fluidity in the pathogenesis of estrogen-induced cholestasis. $J$ Lab Clin Med 112: 679-685, 1988.

SOKOL RJ, STRAKA MS, DAHL R, DEVEREAUX MW, YERUSHALMI B, GUMPRICHT E, ELKINS N, EVERSON G: Role of oxidant stress in the permeability transition induced in rat hepatic mitochondria by hydrophobic bile acids. Pediatr Res 49: 519-531, 2001.

SVENNERHOLM L: Quantitative estimation of sialic acids. II. A colorimetric resorcinol-hydrochloric acid method. Biochim Biophys Acta 24: 604-611, 1957.

TAKKI-LUUKKAINEN IT, MIETTINEN T: Presence of sialic acid and hexosamine in proteins of the aqueous humour. Acta Ophthalmol (Copenh) 37: 138-142, 1959.

UENO K, ANDO S, YU RK: Gangliosides of human, cat, and rabbit spinal cords and cord myelin. J Lipid Res 19: 863871, 1978.

VITEK L, SCHWERTNER HA: The heme catabolic pathway and its protective effects on oxidative stress-mediated diseases. Adv Clin Chem 43: 1-57, 2007. 
VORE M: Estrogen cholestasis: Membranes, metabolites, or receptors? Gastroenterology 93: 643-649, 1987.

VREMAN HJ, STEVENSON DK: Heme oxygenase activity as measured by carbon monoxide production. Anal Biochem 168: 31-38, 1988.

VREMAN HJ, STEVENSON DK: Detection of heme oxygenase activity by measurement of CO. Curr Protoc Toxicol Chapter 9: Unit 9.2, 2001.

ZELENKA J, MUCHOVA L, ZELENKOVA M, VANOVA K, VREMAN HJ, WONG RJ, VITEK L: Intracellular accumulation of bilirubin as a defense mechanism against increased oxidative stress. Biochimie 94: 1821-1827, 2012. 